\title{
Superconductor fault current limiter effect on the performance of doubly-fed induction generators
}

\author{
Farzaneh Mohammadi ${ }^{1}$, Mohammad Molaei ${ }^{2}$ \\ ${ }^{1}$ Department of Electrical and Computer Engineering, Faculty of Shahid Beheshti, AlborzBranch, \\ Technical and Vocational University (TVU), Iran \\ ${ }^{2}$ Electrical Engineer, ITCO Company
}

\begin{tabular}{l} 
Article Info \\
\hline Article history: \\
Received Nov 24, 2019 \\
Revised Feb 25, 2020 \\
Accepted Mar 10, 2020
\end{tabular}

\section{Keywords:}

Crowbar

Doubly-fed induction generator (DFIG)

Fault control

Superconductor fault current limiter (SCFCL)

\begin{abstract}
Between different wind turbine-generator configurations, one of the most accepted and highly regarded structures in the industry is the wind turbine with doubly-fed induction generator. The DFIG wind turbines are very sensitive to grid disturbances especially to voltage drop during grid faults due to relatively low power of the power converters. Fault in a power system causes voltage drop, current increase in stator and rotor coils, and over voltage in the DC shin. Several control methods have been proposed so far. A model based on power electronic instruments and superconductor theory, superconductor fault current limiter (SCFCL), has been proposed in this paper to improve domain and the attenuation time of the parameters under control such as voltage, current, and speed and voltage of the DC link against various types of faults (single-phase, two-phase, and three-phase). In addition to this, in order to compare the results with convectional models (crowbar) and study the innovation of the proposed model, a simulation of the system under two-phase fault and use of crowbar method to control the fault has been conducted using MATLAB-SIMULINK and also, the performance of the proposed method has been assessed.
\end{abstract}

Copyright $\odot 2020$ Institute of Advanced Engineering and Science. All rights reserved.

\section{Corresponding Author:}

Farzaneh Mohammadi,

Faculty of Shahid Beheshti, AlborzBranch,

Technical and Vocational University (TVU), Tehran, Iran.

Email: farzane_mohammade@yahoo.com

\section{INTRODUCTION}

Generators play an important role in converting mechanical to electrical energy. Doubly-fed induction generators (DFIG) is currently utilized in over $85 \%$ of wind turbines [1]. They are typically used due to their advantages such as lower cost, smaller size, easy maintenance, and self-protection against sever overloads and short circuits [2,3]. Figure 1 shows a schematic of an induction generator system with adjustable speed which includes a doubly-fed induction generator alongside a quadric AC-AC converter which is connected to the rotor coil $[4,5]$.

Due to the connection of the DFIG with adjustable speed to the network, active control of the wind turbine during network disturbances is necessary. It must be noted that wind generator must remain connected to the grid for a certain period of time depending on the voltage drop level and this should be considered in designing a wind turbine [6,7]. The amount of voltage drop depends on the location of the fault [8]. Most of the fault in the power transmission systems are transient which represent more than $80 \%$ [9].

Today's common segmentation, including splitting into smaller networks, geographically splitting shines, and choosing transformators' larger impedance will lead to increase in impedance not only in fault, but also in normal conditions which in the latter case, with increase in demand, contrary to quality, power is higher which reduces system's stability. As a result, an instrument with less impedance in normal condition 
and the capability to increase impedance rapidly in fault condition is essential to meet power system requirements. Most of the articles regarding DFIG are about their behavior under balanced and unbalanced network disturbances, some of which used an analytical two-axis model based on finite element method and crowbar resistance [2,10,11] and the results were similar to that of [2] which used a coupled model and different aspects of the work using series dynamic resistance and rotor-side converter analysis have been challenged in other studies [12]. In recent papers, different PI controllers are used for improving transient response of nonlinear DFIG. Various optimization techniques are applied to determine the PI parameter such as: hybrid artificial neutral network [13], GSA algorithm [14]. Furthermore in other researches, PI controllers are tuned and optimised by ICA [15]. The point is that fuses and explosives similar to fuses such as limiters are used up to medium voltage levels. However, these instruments need to be serviced after each trigger and their scalability are limited to higher voltage levels. In contrary, superconductors and semiconductors have the ability to return to the initial state quickly and automatically and they can be used in higher levels. Fault current limiters (especially SCFCLs) have better technical performance compared to older ones. Negligible impedance in normal conditions, quick and effective current limiting in the initial current peaks, and repeated operation and quickly and automatically returning to the initial state are the main.

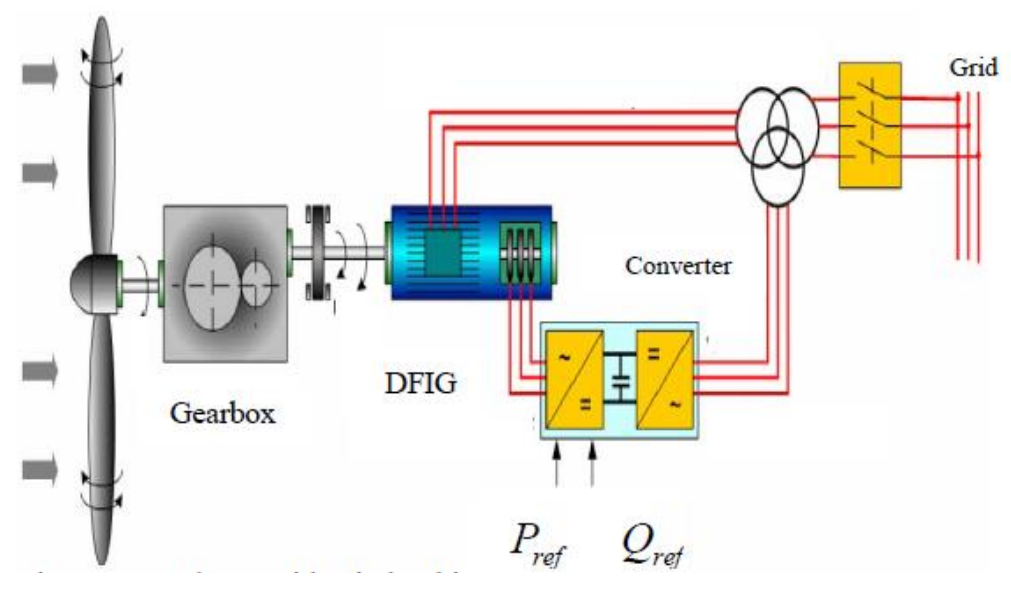

Figure 1. DFIG system [16, 17]

Characteristics of the SCFCLs. This type of the SCFCLs, reaches normal and safe state during a failure and can be manufactured compactly with negligible impedance in normal conditions. With respect to superconductor heating and its shutting down, a certain amount of time is needed for this return which is depended on the superconductor's design. However, it has been proven that the time needed for returning of a thin film superconductor is about a few seconds. It should be said about different types of SCFCLs that many cases have been developed [18-22]. These SCFCLs are divided into three categories: resistive, induction, and bridge. The most common type which is the bridge has the advantages such as automatic switch to current limiter state and without superconductor shutting off. On the other hand, this type cannot limit the persistent fault current [23]. A new design of the SCFCL active single-phase model has been proposed in order to fix this defect and expand its functional range [3]. This new type of the SCFCL which is based on power electronic instruments, modern control theory, and superconductor technique, not only has all of the bridge type advantages, but also it can control persistent fault current and also it is able to compensate the active and reactive power in the main AC circuit in normal state. In the present paper, the mentioned SCFCL effect is proposed as a protective device along the transmission line which can control persistent fault current and compensate the active and reactive power with the help of mentioned characteristics. Furthermore, by using its control method, response time can be reduced compared to other protective devices. In addition to this, it should be mentioned that because the fault detection and control section of the SCFCL are separated for each phase, it can be used for any fault currents which is one of the most important advantages of the model. In the following, to investigate the effect of its protection on fault correction, the DFIG is first simulated under no fault and the results are demonstrated. Then the DFIG is studied and simulated using fault current limiter under different single-phase, two-phase, and three-phase ground faults which happen along transmission line and results have been compared with crowbar and the advantages and disadvantages have been proposed. 


\section{COMPREHENSIVE THEORETICAL BASIS}

In this section, the models of different sections of the network including the DFIG, power converters, crowbar, and the SCFCL are explained.

\subsection{The dfig modeling}

To illustrate the dynamic behavior of the generator in detail, the 5th-order DFIG dynamic model is used which is expressed in d-q synchronous reference vector [12, 23].

\subsection{Power converter modeling}

To model the power converters, semiconductors are considered ideal (no power loss and instant commutation). The electronic power inverter is consisted of ternary commutation cells of two ideal switches. A switching function $\mathrm{Sij}$ is defined for each of the power switches which has ideal commutation and is 1 when the switch is closed and 0 when the switch is open [24].

\subsection{Crowbar modeling}

Crowbar diagram is shown in Figure 2 which demonstrates overall protection effect on fault elimination. Crowbar is consisted of a resistance which is connected to the rotor side through a three-phase diode rectifier bridge and is fed via a three-phase controllable circuit breaker. Circuit breaker is open in normal state; if the rotor current or the DC link voltage is very high, crowbar will close to short circuit the rotor. In addition, converter switching in the rotor side will stop and the switching function Sc is considered for the switches which is 1 for closed and 0 for open state [11].

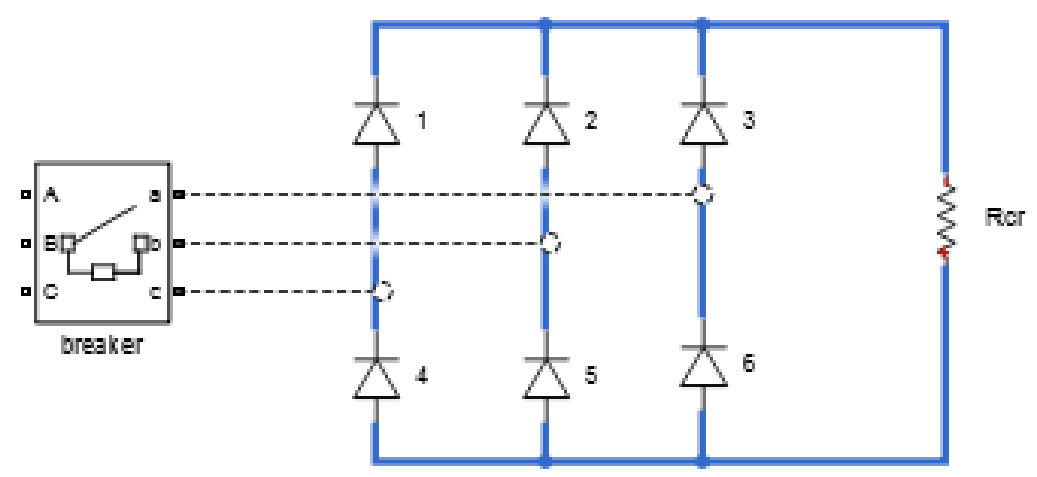

Figure 2. Crowbar circuit [11]

The behavior of such a system during network fault is strongly affected by the crowbar resistance. Little crowbar resistance will cause a larger electrical moment, more overcurrent, and a decrease in rotor voltages. On the other hand, larger crowbar resistance will lead to a less electrical moment, less rotor currents, and higher rotor voltages. Therefore, crowbar resistance needs to be low enough to prohibit high voltages in converter's terminals. It also needs to be high enough to limit rotor current. Crowbar resistance is assumed to be $30 \mathrm{Rr}$ [25].

\subsection{SCFCL modeling}

Figure 3 shows the three-phase active SCFCL circuit structure in a power system which also includes a coreless superconductor transformer and a three-phase voltage PWM converter. For each of the circuit's phase, the Ia, Ib, and Ic line currents, output currents of the PWM converter, and the voltage sources are measured over time. The state of the fault is detected based on the analysis of these signals. In normal state, the output current of the PWM converter will remain at a certain value when the magnetic field of the coreless tans is almost zero. Therefore, the SCFCL will have a little effect on the main circuit [2]. When a fault happens, fault currents will be adjusted to control the impedance limiting which would be in series with the fault phase. Hence, the fault current will be limited. Different control strategy according to different fault currents will be explained in the following section. 


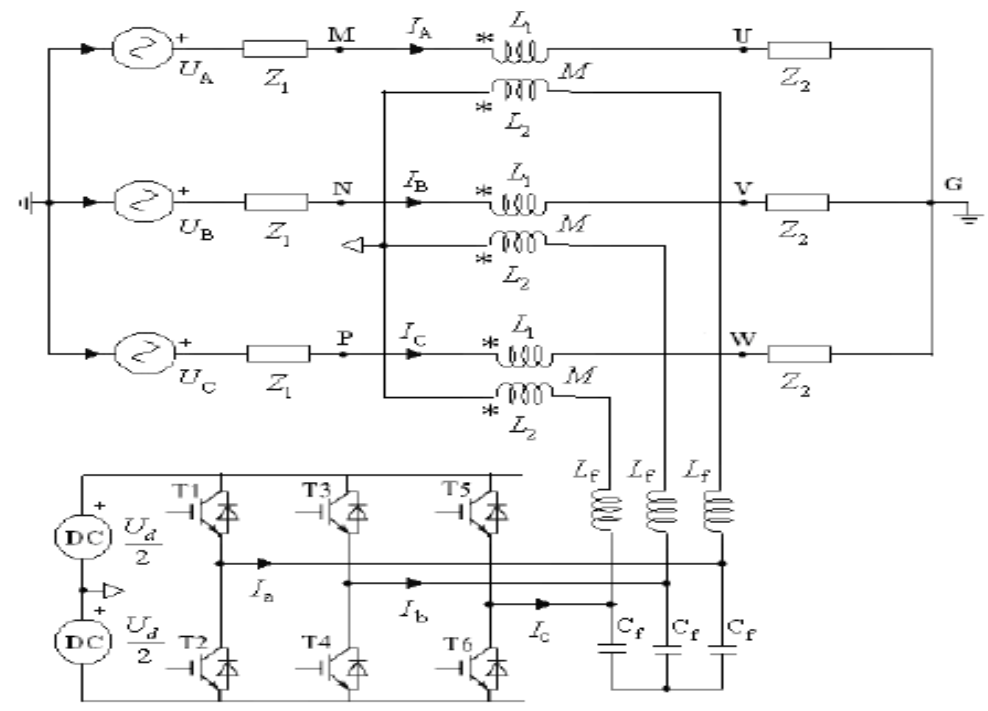

Figure 3. The SCFCL circuit structure [2]

\section{FAULT THEORETICAL BASIS}

\subsection{Single phase fault current}

When single-phase fault current happens in the phase A, the U node will be transformed to ground. The line current in the phase A will reach IAF from IA and the two other phases will remain at their normal state. IAF is calculated through (1),

$$
I_{A F}=\frac{U_{A}+j \omega M I_{A}}{Z_{1}+j \omega L_{1}}
$$

\subsection{Two phase fault current}

Imagine that the phases $\mathrm{A}$ and $\mathrm{B}$ are connected but not through ground (the $\mathrm{A}$ and $\mathrm{B}$ nodes are connected). As a result, the line current of these two phase will be IAF and IBF respectively. The voltage of the fault node, UF, in (5), is obtained from (2)-(4):

$$
\begin{aligned}
& I_{A F}=\frac{U_{A}-U_{F}+A j \omega M I_{A}}{Z_{1}+j \omega L_{1}} \\
& I_{B F}=\frac{U_{B}-U_{F}+j \omega I_{B}}{Z_{1}+j \omega L_{1}} \\
& I_{A F}+I_{B F}=\frac{2 U_{F}}{Z_{2}} \\
& U_{F}=\frac{\left(U_{A}+U_{B}\right)(1-) Z_{2}}{2\left(Z_{1}+Z_{2}+j \omega L_{1}\right)}
\end{aligned}
$$

\subsection{Three phase fault current}

This type of fault is divided into two types: three-phase grounded fault and three-phase non-ground fault. The more important type is the three-phase non-grounded fault in which $\mathrm{U}, \mathrm{V}$, and $\mathrm{W}$ are interconnected, UF is the voltage of the fault node, and line current of each phase is increased to IAF, IBF, and ICF respectively. In this case, (6-(10) are obtained as:

$$
I_{A F}=\frac{U_{A}-U_{F}+A j \omega M I_{A}}{Z_{1}+j \omega L_{1}}
$$




$$
\begin{aligned}
& I_{B F}=\frac{U_{B}-U_{F}+A j \omega M I_{B}}{Z_{1}+j \omega L_{1}} \\
& I_{C F}=\frac{U_{C}-U_{F}+A j \omega M_{C}}{Z_{1}+j \omega L_{1}} \\
& I_{A F}+I_{B F}+I_{C F}=\frac{3 U_{F}}{Z_{2}} \\
& U_{F}=\frac{\left(U_{A}+U_{B}+U_{C}\right)(1-m) Z_{2}}{3\left(Z_{1}+Z_{2}+j \omega L_{1}\right)}
\end{aligned}
$$

Based on the above analysis, the control strategy of this type of the active SCFCL is very flexible, regardless of the fault's type. To analyze the three-phase system, it can be divided into three single-phase system. When it is detected that the fault has taken place in which phase, the output current of the PWM converter of that phase will be adjusted. This topic is related to the control section.

\section{RESULTS AND DISCUSSION}

For simulating the system in Matlab software, the $9 \mathrm{MW}$ wind turbine is connected to the $25 \mathrm{kV}$ network through a $25 / 0.575 \mathrm{kV}$ transformer. The transformer's capacity is $12 \mathrm{MVA}$. The DFIG wind farm is connected to the $120 \mathrm{kV}$ network via a $25 \mathrm{kV}$ line which is $20 \mathrm{~km}$ long and a 120/25 kV transformer. All of the other parameters which are similar to the demo file details of MATLAB are maintained without change. The simulation of the system with SCFCL under three mode; three phase fault, two phase and ground fault are performed. As well as the simulation of the system with crowbar under two-phase interconnection fault for campare is demonstrated.

\subsection{Three phase fault current with SCFCL}

Figure 4 shows the simulation of rotor and stator current waves, stator and the DC link voltage, and rotor speed under the fault. The fault is created in $t=0.28 \mathrm{~s}$ along the line. The results of the DFIG simulation under three-phase fault is demonstrated in Figure 4.

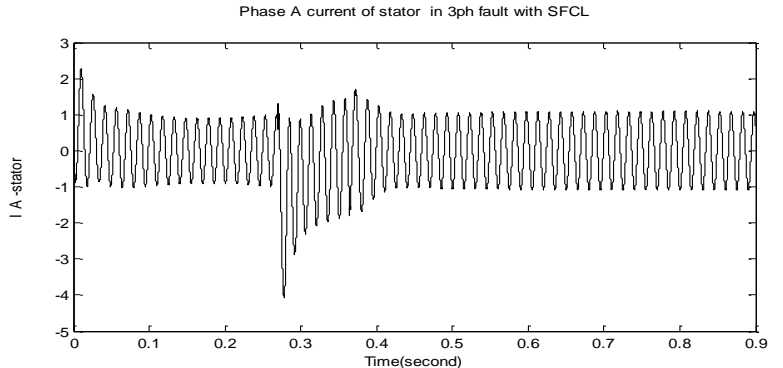

(a). Stator current

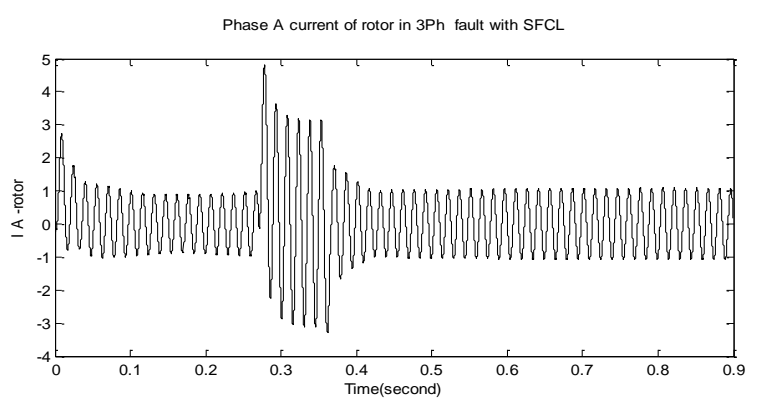

(c). Rotor current

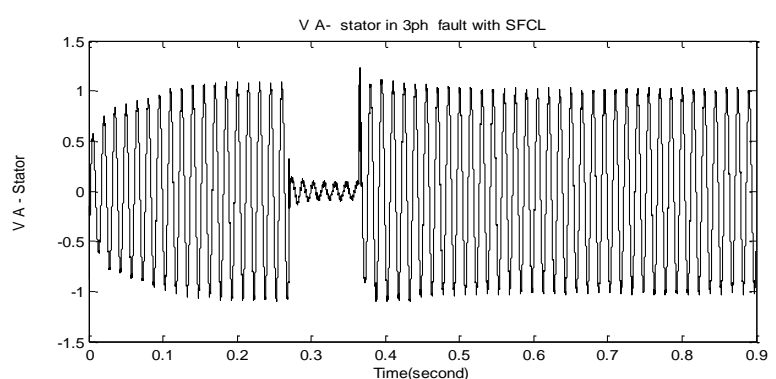

(b). Stator voltage

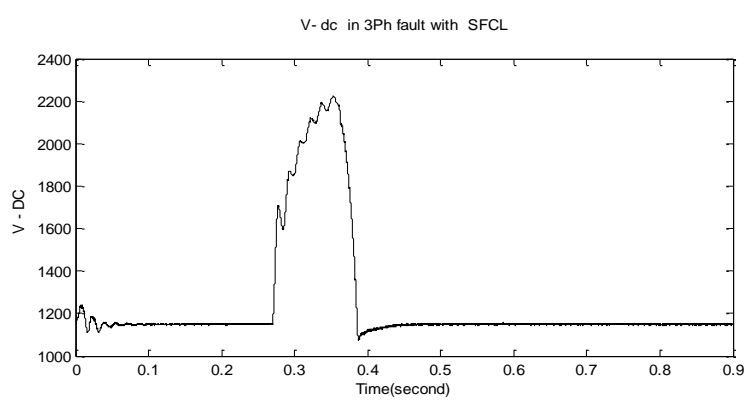

(d). The DC link voltage 


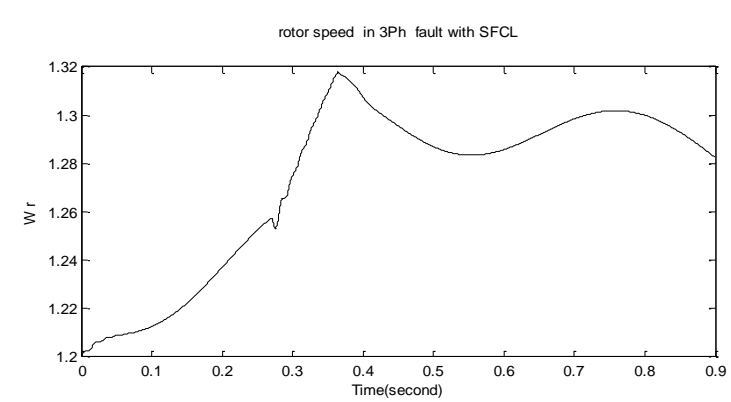

(e). Rotor speed

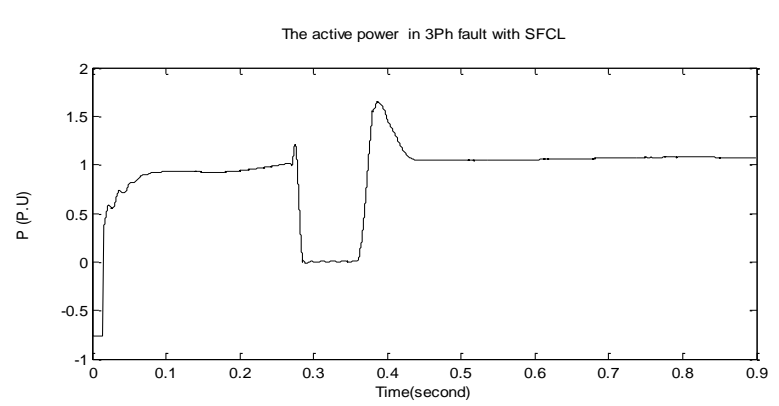

(f). Generator's active power

Figure 4. (a) Stator current (b) Stator voltage (c) Rotor current (d) DC Link voltage (e) Rotor speed and (f) active power in the presence of the three-phase fault with the SCFCL

When a three-phase fault takes place, the currents and voltages of each of the three phases fluctuate. As shown in Figure 4, when the stator's voltage fault is reduced to 0.2 p.u which leads to high transient currents in the stator which according to Figure 4(a) will reach a peak of 4 p.u. Due to the magnetic coupling between stator and rotor, the rotor current will increase to 4.5 p.u as is shown in Figure 4(c). High current in the rotor will cause the DC link voltage to fluctuate and increase from the initial value of $1150 \mathrm{~V}$ to $2200 \mathrm{~V}$.

Higher rotor current will lead to more moment which causes the rotor to accelerate to $1.32 \mathrm{p} . \mathrm{u}$ while consuming a reactive power of 0.9 p.u from the network. As can be observed from Figure 4 , all of the transient states will be attenuated with the SCFCL effect after $0.1 \mathrm{~s}$ and the fluctuating values will return to their nominal and initial values.

\subsection{Two phase interconnection fault with SCFCL}

Results of the DFIG simulation under two-phase interconnection fault is shown in Figure 5. In this fault, two phases (A and B) are connected together. The two-phase fault occurs when it has the same analysis as the two-phase ground fault. According to Figure 5, when the stator voltage fault is reduced to 0.6 p.u which leads to high transient currents in the rotor which will reach a peak of 3 p.u. Because of the magnetic coupling between rotor and stator, the rotor current will increase to 3.7 p.u. High current in the rotor will cause the DC link voltage to fluctuate and increase from the initial value of $1150 \mathrm{~V}$ to $1580 \mathrm{~V}$. Higher rotor current will lead to more moment which causes the rotor to accelerate to 1.32 p.u while consuming a reactive power of 1.5 p.u from the network. As can be observed from Figure 5, all of the transient states are attenuated with the SCFCL effect and the fluctuating values will return to their nominal and initial values.

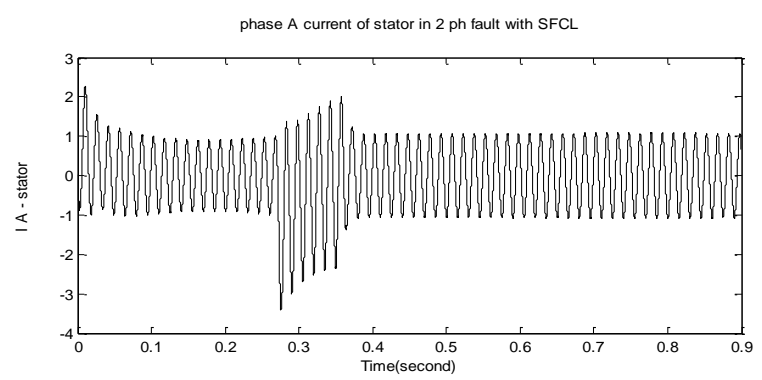

(a). Stator phase current

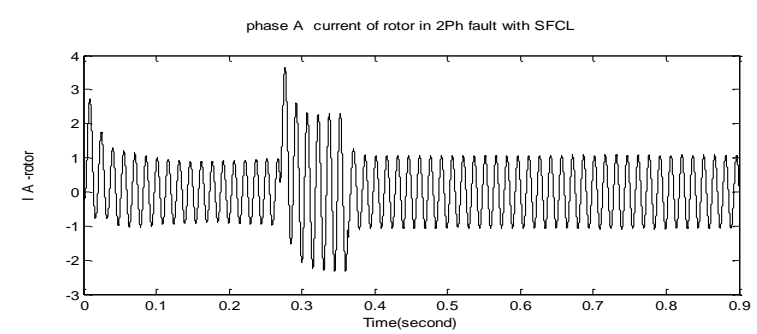

(c). Rotor phase current

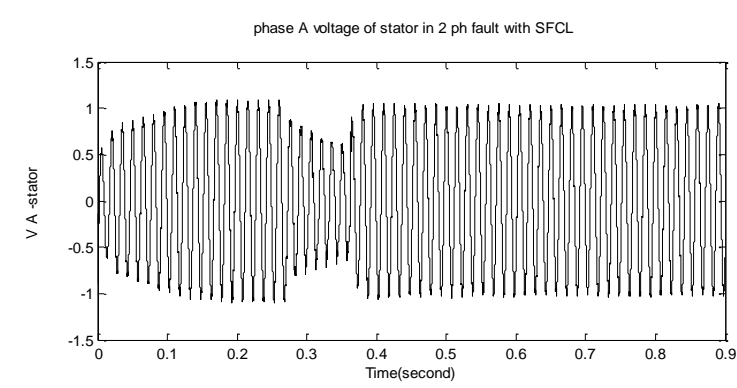

(b). Stator phase voltage

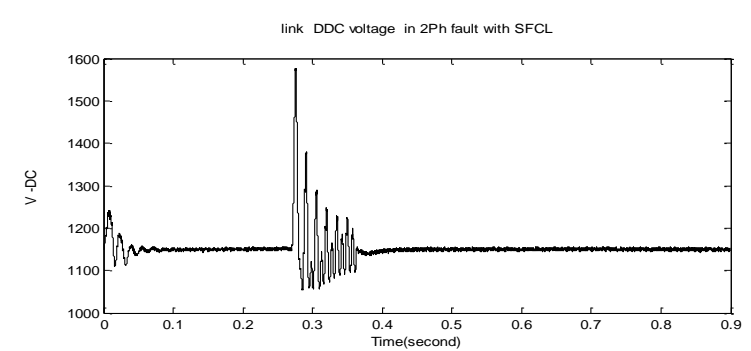

(d). The DC link voltage 


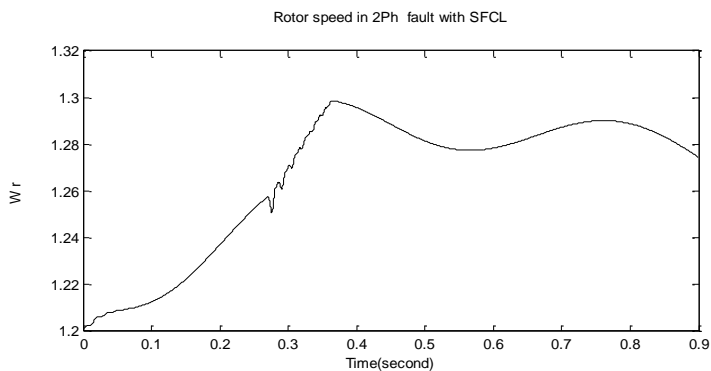

(e). Rotor speed

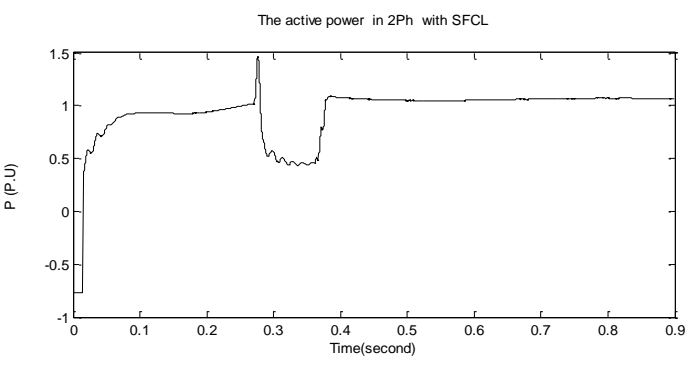

(f). Generator reactive power

Figure 5. (a) Stator current (b) Stator voltage (c) Rotor current (d) DC Link voltage (e) Rotor speed (f) Reactive power in the presence of the two-phase fault with the SCFCL

\subsection{Single phase graound fault with SCFCL}

The results of the single-phase ground fault or in other words, the connection of phase A to ground is shown in Figure 6.

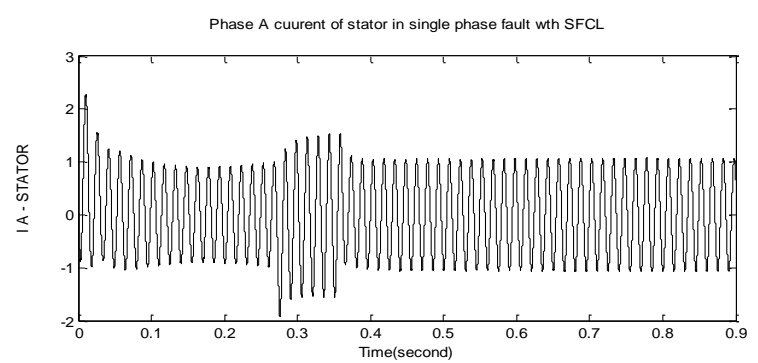

(a). Stator phase current

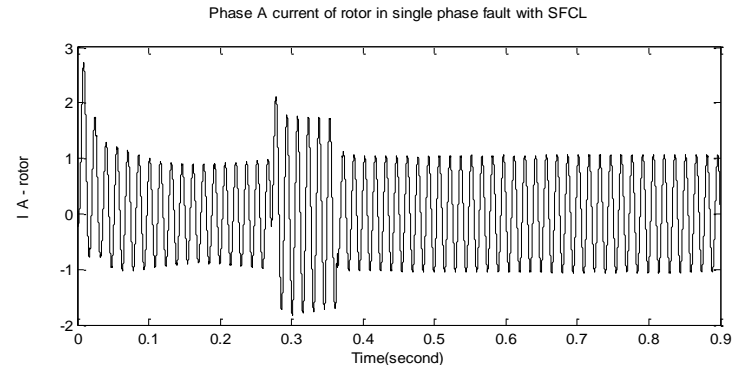

(c). Rotor phase current

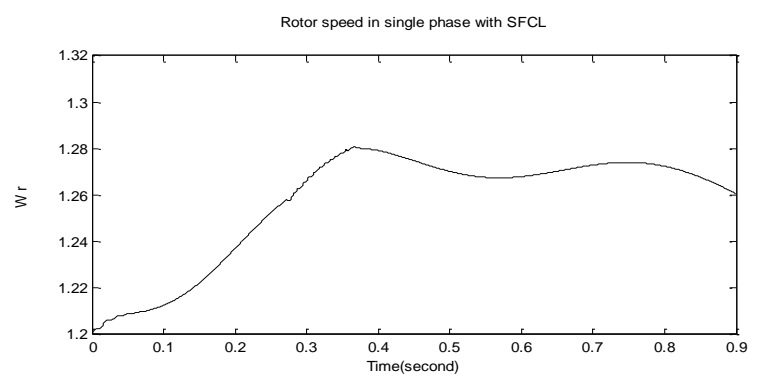

(e). Rotor speed

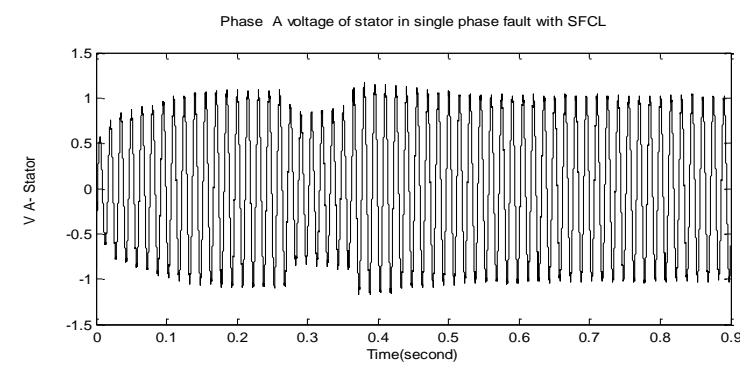

(b). Stator phase voltage

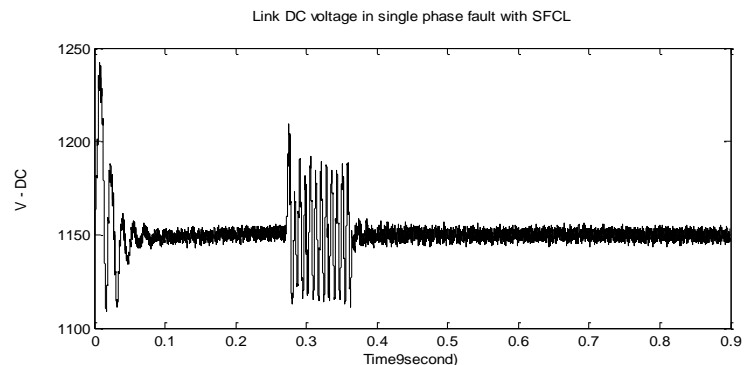

(d). The DC link voltage

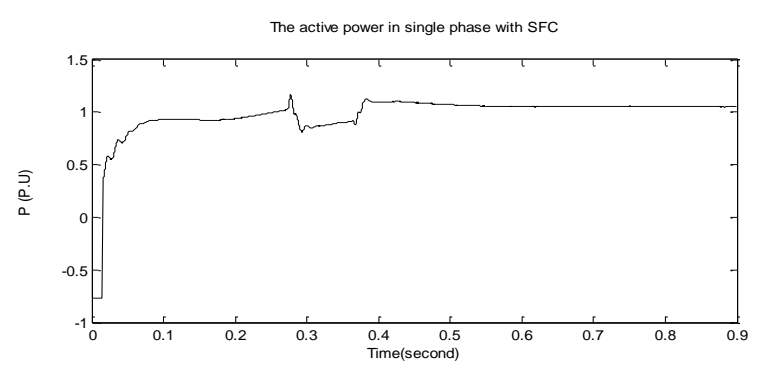

(f). Generator active power

Figure 6. (a) Stator current (b) Stator voltage (c) Rotor current (d) DC Link voltage (e) Rotor speed (f) Reactive power in the presence of the single-phase fault with the SCFCL

When a fault takes place in the phase A and it is connected to the ground, according to Figure 6, the stator voltage is reduced to 0.7 p.u. The stator current reaches a peak of 2 p.u. Because of the magnetic 
coupling between rotor and stator, the rotor current will increase to 2 p.u. High current in the rotor will cause the DC link voltage to fluctuate and increase to $1210 \mathrm{~V}$. The rotor accelerates to $1.29 \mathrm{p}$.u while consuming a reactive power of 0.4 p.u from the network. As can be observed from Figure 6, all of the transient states are attenuated with the SCFCL effect and the fluctuating values will return to their nominal and initial values.

\subsection{Two-phase interconnection fault using crowbar}

The diagram of the Figure 7 shows the simulated shape of the stator and rotor current waves, the DC link and stator voltage, and rotor speed under fault using crowbar.

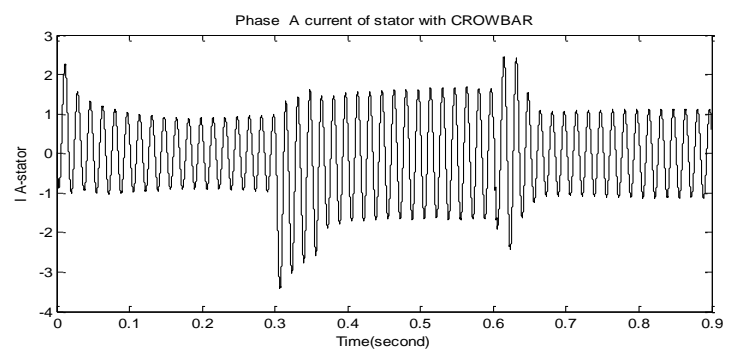

(a). Stator phase current

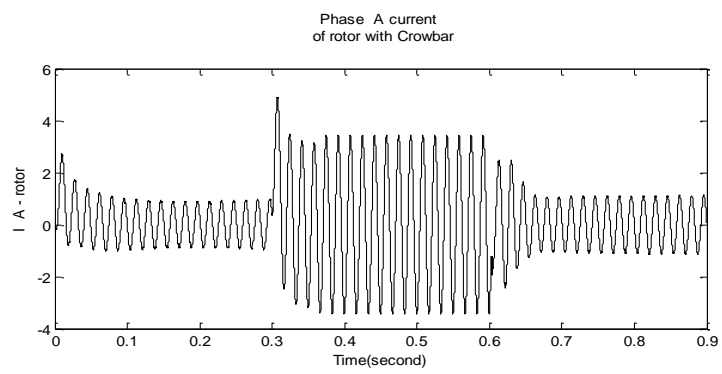

(c). Rotor phase current

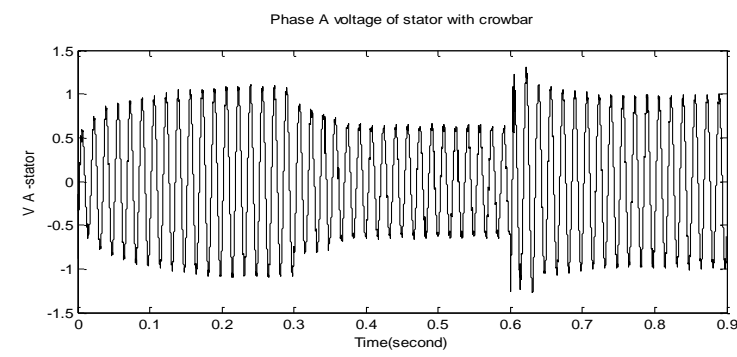

(b). Stator phase voltage

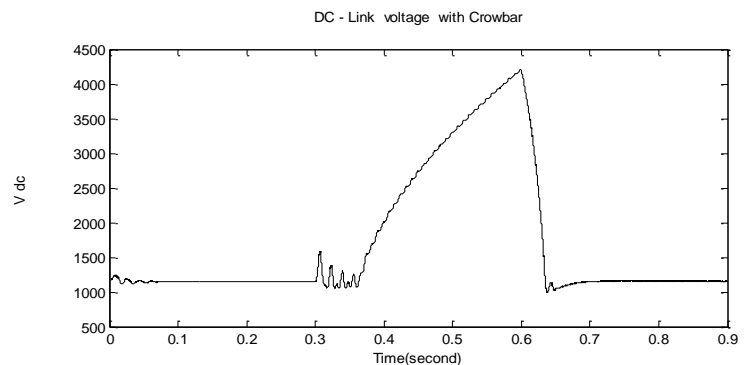

(d). The DC link voltage

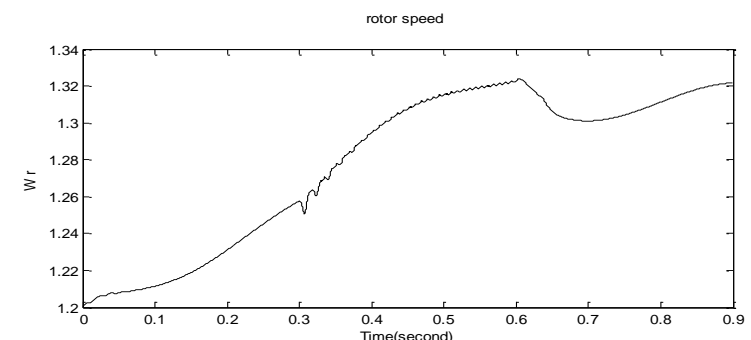

(e). Rotor speed

Figure 7. (a) Stator current (b) Stator voltage (c) Rotor current (d) DC Link voltage (f) Rotor speed in the presence of the two-phase fault using crowbar

During the fault, the DFIG terminal voltage decreases which causes rotor and stator flux to decrease in the generator. This will cause the decrease of the active power. Because the stator flux has decreased, the magnetization stored in the magnetic field is released. Immediately after the fault, the generator will absorb reactive power from the network to magnetize. When a fault occurs, the network side converter is no longer able to transfer power to the rotor side converter and hence, will receive the excess power which is provided by the capacitor voltage which will lead to rapid DC voltage increase.

Because of the resulted high transient currents in the rotor with peak values more than 4 p.u, the DC link voltage will be increased up to 4 times. The high transient current is seen in the stator side whose value is about 2.5 p.u. The rotor speed will fluctuate. The line current will also be increased up to 4 times. The time needed for attenuating the fluctuations is crucial here. As can be seen, the attenuation time in the SCFCL state is much less than crowbar and this confirms the present paper's innovation. Tables 1 and 2 illustrate the summary of the system response. 
Table 1. Comparison of system with SCFCL and crowbar

\begin{tabular}{ccc}
\multicolumn{3}{c}{ At two phae interconnection fault } \\
\hline Parameter & Crowbar & SCFCL \\
& & \\
Voltage(p.u) & $-50 \%$ & $-50 \%$ \\
Current(p.u) & 5 & 3.7 \\
DC Link Voltage(v) & 4500 & 1550 \\
Damping time(sec) & 0.32 & 0.1 \\
\hline
\end{tabular}

Table 2. Response of the faulty system with SCFCL

\begin{tabular}{crcc}
\hline & \multicolumn{3}{c}{ Fault } \\
\hline Parameter & 1P-G & 2P & 3P-G \\
& & & \\
Voltage (\%) & -10 & -50 & -80 \\
Current(p.u) & 2 & 3.7 & 4.2 \\
DC Link & 1.04 & 1.3 & 1.8 \\
Voltage (\%) & & & \\
Damping time(sec) & 0.08 & 0.1 & 0.11 \\
\hline
\end{tabular}

\section{CONCLUSIONS}

In the last two decades, wind power generation has undergone a significant development. The DFIGs' sensitivity to the unstable network, voltage drop, and network fault has led to different control strategies including converter vector control being used. However, this method does not have acceptable control when the voltage and rotor current are low it should be mentioned that this capability is limited by converters' capacity. Therefore, the need for other controlling and limiting instrument such as crowbar and SCFCL in the rotor's higher currents is inevitable.

In the present study, in order to investigate limiting effect of the SCFCL and comparing it to other functional instrument such as crowbar, the single-phase, two-phase, and three-phase fault along the line for the DFIG circuit using SCFCL and two-phase fault for the DFIG circuit using crowbar are studied. The important point regarding crowbar is the time it needs to reach zero, because this is the parameter which decides when the rotor side converter can control the power. It should be mentioned that the larger the resistance of the crowbar is, the longer it would take for the crowbar current to reach zero. Another problem that crowbar has, is that when crowbar is in the circuit, the DFIG loses the ability to control active and reactive power and consumes active power from the network which causes excessive voltage drop, generator speed increase, and wind turbine instability. On the other hand, the SCFCL has improved all of the above and has other advantages such as fault accurate and rapid detection method which can cause the fault current to decrease to an acceptable level when combined with a logical reaction of a PWM. Since fault control and detection sections are separated for each phase in the SCFCL, it can be used for any fault current. Furthermore, it is obvious that while using the SCFCL for the two-phase interconnection problem, in the early peaks after the fault, stator voltage drop is less than that of crowbar and rotor current increase, stator current, and the DC link voltage is similar to that of crowbar for 50-70\% of these parameters. The other thing that further confirms the method innovation is the time needed to limit the fault, which is noticeably less in the case of the SCFCL.

\section{REFERENCES}

[1] S.A. Kamran, et al., "Voltage Oriented Decoupled Control Scheme for DIG's Grid Side Converter," TELKOMNIKA (Telecommunication, Computing, Electronics and Control), vol. 16, no. 3, pp. 1027-1033, June 2018.

[2] S. Seman, et al., "Performance study of a doubly fed wind-power induction generator under network disturbances," IEEE Transactions on Energy conversion, vol. 21, pp. 883-890, 2006.

[3] L. Chen, et al., "Operational characteristics of three-phase active superconducting fault current limiter in power system," in 2008 International Conference on Electrical Machines and Systems, pp. 4455-4459, 2008.

[4] X. Zhang, et al., "Response and protection of DFIG system under grid fault," in 2010 Asia-Pacific Power and Energy Engineering Conference, pp. 1-5, 2010.

[5] Amin Jalilian, et al., "Low voltage ride-through enhancement of DFIG-based wind turbineusing DC link switchable resistive type fault current limiter," Electrical Power and Energy Systems, pp. 104-119, 2016.

[6] A. M. S. Y, et al.,"Dynamic performance comparison of DFIG and FCWECS during grid faults," TELKOMNIKA (Telecommunication, Computing, Electronics and Control), vol. 17, no. 2, pp. 1040-1046, April 2019.

[7] S. Tohidi, et al., "A comprehensive review of low voltage ride through of doubly fedinduction wind generators," Renewable and Sustainable Energy Reviews, pp. 412-419, 2016.

[8] B. I. Nass, et al., "Methods for reduction of voltage unbalance in weak grids connected to wind plants," in IEEE/CIGRE Workshop on Wind Power and the Impacts on Power Systems, 2002.

[9] M. K. M. Mahrous Ahmed, et al., "Performance investigation of multi-level inverter for DFIG during grid autoreclosure operation," International Journal of Power Electronics and Drive System (IJPEDS), vol. 10, no. 1, March 2019.

[10] S. R. Kalantarian, et al., "A new crowbar protection method for improvement in performance of doubly fed induction generator under fault conditions," in 2011 10th International Conference on Environment and Electrical Engineering, 2011, pp. 1-4.

[11] A. Noubrik, et al., "Analysis and simulation of a 1.5 MVA doubly fed wind-power in MATLAB SimPowerSystems using crowbar during power systems disturbances," in 2011 International Conference on Communications, Computing and Control Applications (CCCA), pp. 1-6, 2011. 
[12] K. Okedu, et al., "Protection schemes for DFIG considering rotor current and DC-link voltage," in 2011 International Conference on Electrical Machines and Systems, pp. 1-6, 2011.

[13] O. Y. P. Venu Madhav G, "A New Hybrid Artificial Neural Network Based Control of Doubly Fed Induction Generator," International Journal of Electrical and Computer Engineering (IJECE), vol. 5, no. 3, pp. 379-390, 2015.

[14] M. I. A. Saher Albatran, et al., "Gravitational-Search Algorithm for Optimal Controllers Design of Doubly-fed Induction Generator," International Journal of Electrical and Computer Engineering (IJECE), vol. 8, No. 2, April 2018.

[15] M. R. Zahra Rafiee, et al., "The voltage dip and doubly fed induction generator with considering uncertainty conditions," Bulletin of Electrical Engineering and Informatics (BEEI), vol. 9, No. 1, pp. 30-38, Feb 2020.

[16] S. R. Kalantarian, et al., "A new crowbar protection method for improvement in performance of doubly fed induction generator under fault conditions," 2011 10th International Conference on Environment and Electrical Engineering, pp. 1-4, 2014.

[17] M.Sunanda, "Dynamic Stability Improvement Analysis for An Integrated Grid-Connected Dfig Based Wind Farm," International Journal for Recent Developments in Science \& Technology, vol. 2, pp. 67-73, Jan 2018.

[18] C. A. Baldan, et al., "Test results of a superconducting fault current limiter using YBCO coated conductor," IEEE Transactions on Applied Superconductivity, vol. 17, pp. 1903-1906, 2007.

[19] J. Kozak, et al., "Design and testing of $230 \mathrm{~V}$ inductive type of superconducting fault current limiter with an open core," IEEE Transactions on applied superconductivity, vol. 15, pp. 2031-2034, 2005.

[20] S.-H. Lim, et al., "Fault current limiting characteristics of DC dual reactor type SFCL using switching operation of HTSC elements," IEEE transactions on applied superconductivity, vol. 16, pp. 723-726, 2006.

[21] Z. Q. Z. Y. Z. Youqing, et al., "An Improved Double-Bridge Mixed Rectifier Type High Temperature Superconducting Fault Current Limiter [J]," Transactions of China Electrotechnical Society, vol. 2, 2007.

[22] A.Y. Hatata, et al., "Application of resistive super conductor faultcurrent limiter for protection of grid-connected DGs," Alexandria Engineering Journal, vol. 57, pp. 4229-4241, Dec 2018.

[23] X. Liye, et al., "Active Superconducting Fault Current Limiter," Chinese Journal of Low Temperature Physics, vol. 25, pp. 302-308, 2003.

[24] B. Francois, et al., "A new approach for synthesizing logic connection controllers in power converters," in EPE'95, pp. 693-398, 1995.

[25] L. Peng, et al., "Improved crowbar control strategy of DFIG based wind turbines for grid fault ride-through," in 2009 Twenty-Fourth Annual IEEE Applied Power Electronics Conference and Exposition, pp. 1932-1938, 2009.

\section{BIOGRAPHIES OF AUTHORS}

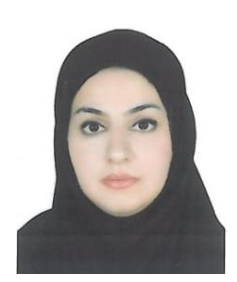

Farzaneh Mohammadi, was born in 1984 in Iran. She works in Faculty of Shahid Beheshti, AlborzBranch, Technical and Vocational University (TVU), located in Iran as a member of the Academic Staff and currently she is the head of electrical and electronic group. Also she has been the consultant of the power plant and petrochemical, oil and gas plants in Iran since 2010.

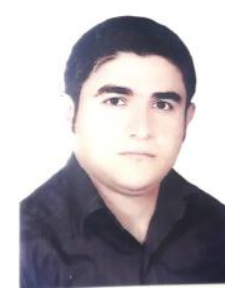

Mohammad Molaei, was born in Iran on 1981. He received his BSC degree from Najafabad University, MSc degree from Arak University. He is the head of Itco company in Iran. His research interest includes optimization of the power plants output, stability in power system, protection of network and renewable resources. He consulted to a variety of industry and public sectors in Iran in the fields of energy engineering and power plants. He is currently appointed as a gas power plant manager. 